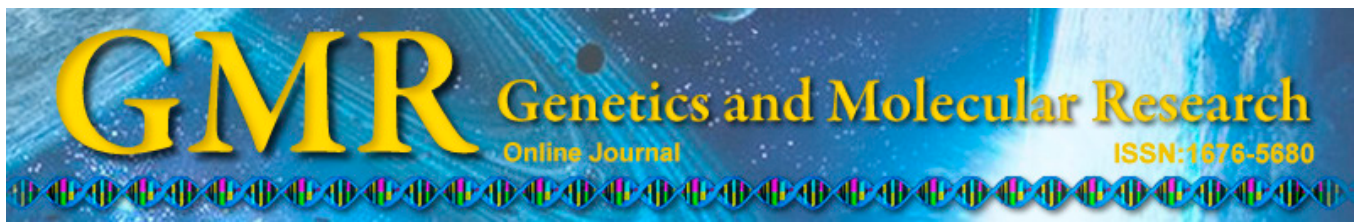

\title{
Expression analysis of dihydroflavonol 4-reductase genes in Petunia hybrida
}

\author{
Y.X. Chu ${ }^{1,2}$, H.R. Chen ${ }^{1}$, A.Z. Wu ${ }^{1,2}$, R. Cai ${ }^{2}$ and J.S. Pan ${ }^{2}$ \\ ${ }^{1}$ Institute for Agri-Food Standards and Testing Technology, \\ Shanghai Academy of Agricultural Sciences, Shanghai, China \\ ${ }^{2}$ School of Agriculture and Biology, Shanghai Jiaotong University, \\ Shanghai, China
}

Corresponding author: J.S. Pan

E-mail: jspan71@sjtu.edu.cn

Genet. Mol. Res. 14 (2): 5010-5021 (2015)

Received July 25, 2014

Accepted December 9, 2014

Published May 12, 2015

DOI http://dx.doi.org/10.4238/2015.May.12.4

\begin{abstract}
Dihydroflavonol 4-reductase (DFR) genes from Rosa chinensis (Asn type) and Calibrachoa hybrida (Asp type), driven by a CaMV $35 \mathrm{~S}$ promoter, were integrated into the petunia (Petunia hybrida) cultivar 9702. Exogenous DFR gene expression characteristics were similar to flower-color changes, and effects on anthocyanin concentration were observed in both types of $D F R$ gene transformants. Expression analysis showed that exogenous $D F R$ genes were expressed in all of the tissues, but the expression levels were significantly different. However, both of them exhibited a high expression level in petals that were starting to open. The introgression of DFR genes may significantly change DFR enzyme activity. Anthocyanin ultraperformance liquid chromatography results showed that anthocyanin concentrations changed according to DFR enzyme activity. Therefore, the change in flower color was probably the result of a DFR enzyme change. Pelargonidin 3-O-glucoside was found in two different transgenic petunias, indicating that both CaDFR and RoDFR could catalyze dihydrokaempferol. Our results also suggest that transgenic
\end{abstract}


petunias with $D F R$ gene of Asp type could biosynthesize pelargonidin 3-O-glucoside.

Key words: Calibrachoa hybrida; Rosa chinensis; Petunia hybrida; Dihydroflavonol 4-reductase genes

\section{INTRODUCTION}

Petunia is a relatively fast-breeding dicot that is easily maintained in the greenhouse, and produces hundreds of seeds from a single pollination. Flavonoid synthesis in Petunia hybrida offers an excellent model system to study the regulation of gene expression in higher plants (Beld et al., 1989).

Anthocyanins are the primary flower pigments in higher plants (Yang et al., 2013). Flower breeders have produced a wide array of colors by exploiting mutations, or the variable expression of anthocyanin biosynthesis. However, very few plant species are capable of producing all possible flower colors. The limited color range within species can be due to the absence, mutation, or abundance of an anthocyanin biosynthetic gene. Carnations, chrysanthemums, and roses do not produce purple delphinidin anthocyanins because they lack the activity of flavonoid 3',5'-hydroxylase (Seo et al., 2007). Petunia produces very little orange pelargonidin-type anthocyanin, because its enzyme, dihydroflavonol 4-reductase (DFR), does not efficiently catalyze the reduction of dihydrokaempferol (DHK) (Matsubara et al., 2005). DFR, which catalyzes the reduction of dihydroflavonols to leucoanthocyanins, is a key enzyme in the biosynthesis of anthocyanidins, proanthocyanidins, and other flavonoids of importance in plant development and human nutrition (Li et al., 2012). DFR uses NADPH as a cofactor to catalyze the reduction of dihydroflavonols to their respective leucoanthocyanidins, and these are common precursors for anthocyanin and proanthocyanidin biosynthesis (Zhou et al., 2008). The colorless, unstable leucoanthocyanidins are immediate precursors in the synthesis of anthocyanins, which are the main water-soluble pigments found in flowers and fruits. In some plants, DFR is reported to have broad substrate acceptance; DFR accepts dihydroflavonols as substrates, but it also reduces flavanone as flavanone 4-reductase (FNR) to produce 3-deoxyanthocyanidin ( $\mathrm{Li}$ et al., 2012). Research suggests that the 134th asparagine plays an important role in substrate specificity; it is conserved in most DFRs (categorized as the Asn type), but some DFRs contain aspartic acid (categorized as the Asp type) (Johnson et al., 2001). Petunia DFR does not efficiently reduce DHK; therefore, little pelargonidin is synthesized by anthocyanidin synthase (Oud et al., 1995). However, petunia DFR reduces dihydroquercetin (DHQ) and dihydromyricetin (DHM) to make red cyanidin and purple delphinidin anthocyanins, respectively (Forkmann and Ruhnau, 1987; Tanaka et al., 2005). Advances in molecular biology and plant transformation have enabled the manipulation of flower color, including the production of novel flower colors and the enhancement of weaker colors (Qi et al., 2013). The modification of flower color using genetic engineering was reported for the first time by Meyer et al. (1987), when a novel color was produced in P. hybrida integrated with maize $A 1$. However, the brick flowers of the primary $A 1$ transformants were pale, and exhibited variability in their pigmentation during growth. Subsequently, a number of $D F R$ genes from different plants, such as gerbera and rose, were transferred to the petunia (van der Krol et al., 1990; Mol et al., 1995; Tanaka et al., 1995; Johnson et al., 1999; Tanaka et al., 2005); the changes were manifold. Transformants of the petunia R27 DFR gene exhibited a reduction 
in flower pigmentation in sector or ring patterns, and even white corolla (van der Krol et al., 1990). A bright-orange petunia variety was achieved by crossing different transgenic petunia lines containing the maize DFR gene with their elite breeding material (Mol et al., 1995). A pale-pink petunia cultivar was transformed using a binary vector that contained rose $D F R$ cDNA. The petals and anthers of the resultant transgenic petunia plants were salmon pink and contained pelargonidin (Tanaka et al., 1995). Elomaa et al. (1995) concluded that the properties of the transgene itself strongly influenced the inactivation process.

Overexpression of a heterologous gene is a common strategy for improving plant traits; however, this strategy is not always successful in achieving the desired result (Katsumoto et al., 2007; Yong et al., 2009). Identification of the optimal genes that produce the desired effect requires a broad testing of genes from multiple sources. In our study, exogenous DFR from Rosa chinensis (Asn type) and Calibrachoa hybrida (Asp type), under the control of a CaMV 35S, were integrated into the red petunia cultivar, 9702. The main objective was to elucidate exogenous DFR expression characteristics in transformants, and their effect on the anthocyanin content.

\section{MATERIAL AND METHODS}

\section{Plant materials}

DFR from R. chinensis (GenBank No. D85102) and C. hybrida (GenBank No. $\mathrm{KC} 140106)$ that was under the control of the $35 \mathrm{~S}$ promoter was transformed into petunia variety 9702 , as described by Chu et al. (2014). Three 9H transgenic plants $(9 \mathrm{H} 30,9 \mathrm{H} 31$, and 9H33) and three 9R plants (9R8, 9R9, and 9R12) were grown in a greenhouse with the original petunia cultivar 9702.

\section{Methods}

\section{DFR gene expression in the petunia}

A quantitative real-time polymerase chain reaction (PCR) was conducted to investigate the expression patterns of $C a D F R, R o D F R$, and endogenous $D F R$ in different tissues of cultivar 9702 and its transformants. Using liquid nitrogen, we froze 200-mg samples of leaves, flower bud type I (the corolla was shorter than the calyx), flower bud type II (1.5-3.5 $\mathrm{cm}$ in length, with a yellow or green corolla), flower bud type III $(3.5-5 \mathrm{~cm}$ in length, with a red corolla), petals starting to open (the inside of the throat was visible), petals from fully opened flowers, and anthers. Total RNA from these samples was extracted using a plant total RNA purification kit (Shanghai Laifeng Biotech Co. Ltd., Shanghai, China), followed by DNase treatment (TaKaRa Biotechnology (Dalian) Co. Ltd., Dalian, China) to remove all of the genomic DNA. First-strand cDNA was synthesized from 500 ng RNA using an AMV First-Strand cDNA Synthesis Kit (BBI, Italy), following the manufacturer protocol. In a $0.2-$ $\mathrm{mL}$ tube, combine $1 \mu \mathrm{L}$ primer Random Primer $\mathrm{p}(\mathrm{dN})_{6}(0.2 \mu \mathrm{g} / \mu \mathrm{L})$ and $5 \mu \mathrm{L}$ RNA. Adjust the volume to $10 \mu \mathrm{L}$ with DEPC-treated water. Denature the RNA and primer by incubating at $65^{\circ} \mathrm{C}$ for $5 \mathrm{~min}$ and then place on ice. Vortex the 5X cDNA Synthesis Buffer for $5 \mathrm{~s}$ immediately before the next step. Add $4 \mu \mathrm{L} 5 \mathrm{X}$ cDNA Synthesis Buffer, $2 \mu \mathrm{L} 10 \mathrm{mM}$ dNTP mix, 2 $\mu \mathrm{L}$ Rnase inhibitor $(20 \mathrm{U} / \mu \mathrm{L})$ and $2 \mu \mathrm{L}$ AMV Reverse Transcriptase $(10 \mathrm{U} / \mu \mathrm{L})$. Transfer the 
reaction tube to a thermal cycler preheated to the appropriate cDNA synthesis temperature and incubate. Use the following temperatures and incubation times: $5 \mathrm{~min}$ at $37^{\circ} \mathrm{C}, 30-60 \mathrm{~min}$ at $42^{\circ} \mathrm{C}$. Terminate the reaction by incubating at $70^{\circ} \mathrm{C}$ for $10 \mathrm{~min}$. The final cDNA products were diluted 8-fold prior to their use in a real-time PCR. Real-time amplification was performed, with first-strand cDNA as the template, on an ABI StepOnePlus ${ }^{\mathrm{TM}}$ Real-Time PCR System (Applied Biosystems). The total reaction volume was $20 \mu \mathrm{L}$, and the conditions were as follows: first denaturation at $95^{\circ} \mathrm{C}$ for $2 \mathrm{~min}$, then 40 amplification cycles were carried out, consisting of denaturation at $95^{\circ} \mathrm{C}$ for $10 \mathrm{~s}$, annealing at $60^{\circ} \mathrm{C}$ for $40 \mathrm{~s}$, and extension at $72^{\circ} \mathrm{C}$ for $30 \mathrm{~s}$. The abundance of $18 \mathrm{~S}$ rRNA was used as an internal control (Chen et al., 2004), and relative expression was determined by normalizing the values to that of 18S rRNA (Chen et al., 2004). Primers for real-time amplification were designed based on the coding sequences of C. hybrida (GenBank No. KC140106.1), P. hybrida (GenBank No. KC140107.1), and $R$. hybrida (Submission No. 1666994). Determination of the amplification efficiency and the calculation of the RNA transcript levels, was conducted using the StepOne Software.

The reaction mixture included $1 \mu \mathrm{L}$ cDNA, $10 \mu \mathrm{L}$ SYBR $^{\circledR}$ Green qPCR Master Mix, $2 \mu \mathrm{L}$ primers $\left(10 \mu \mathrm{M}\right.$ forward and reverse, respectively), and $7 \mu \mathrm{L} \mathrm{ddH}_{2} \mathrm{O}$. The primers used were as follows: 18s-F, 5'-GATCGGAGTAATGATTAACAGGG-3', 18s-R, 5'-GGCATCGTTTATGGTTGAGAC-3'; Pe-F, 5'-GTCCGACTTTCCAACTTCCATA-3', PeR, 5'-GCCAAGAGCCAATAAATCCAG-3'; Ca-F, 5'-GATGTGGCTAAGATGGTCCGA-3', Ca-R, 5'-GCCCCTTTATACATATCCTCCAA-3';Ro-F,5'-CCAAGGACCCTGAGAACGA-3', Ro-R, 5'-ATTGACAGATCCAGCCGAAG-3'. Standard curves were constructed using a series of 5-fold dilutions of cDNA (spanning five orders of magnitude). The slopes of the standard curves were used to calculate the gene-specific PCR amplification efficiency. Gene expression analysis was conducted using the $2^{-\Delta \Delta \mathrm{Ct}}$ method (relative quantification; Schmittgen and Livak, 2008). The change in DFR gene expression was calculated using the PeDFR expression level in the leaf of the cultivar 9702.

\section{Measurement of DFR activity}

Plant samples $(0.25 \mathrm{~g})$ were crushed under liquid nitrogen, and total protein was extracted with $1 \mathrm{~mL}$ phosphate buffer solution $\left(137 \mathrm{mM} \mathrm{NaCl}, 8.1 \mathrm{mM} \mathrm{Na} \mathrm{HPO}_{4}, 2.68 \mathrm{mM}\right.$ $\mathrm{KCl}$, and $\left.1.47 \mathrm{mM} \mathrm{KH}_{2} \mathrm{PO}_{4}, \mathrm{pH} 7.4\right)$. After centrifugation (12,000 rpm) for $20 \mathrm{~min}$ at $4^{\circ} \mathrm{C}$, the supernatant was used for further analysis. DFR activity was measured according to Hayashi et al. (2005). The reaction mixture contained $25 \mathrm{mM}$ Tris- $\mathrm{HCl}, \mathrm{pH} 7.0,50 \mu \mathrm{M}$ dihydroquercetin, $35 \mu \mathrm{L}$ enzyme extract, and $80 \mu \mathrm{L} 4 \mathrm{mM}$ NADPH.

\section{Ultra-performance liquid chromatography (UPLC) analysis of anthocyanins}

The equipment used was a 2695 Waters Acquity UPLC system, and the organic solvents were HPLC grade (acetonitrile, methanol, and formic acid); re-distilled water was also used. The mobile phase was filtered through a $0.45-\mu \mathrm{m}$ filter (J.T. Baker, Phillipsburg, NY, USA), and the anthocyanins were separated by gradient elution using solvent A (methanol: acetonitrile:water:formic acid, 22.5:22.5:45:10) and solvent B (water:formic acid, 90:10) (Luczkiewicz and Cisowski, 1998). The gradient program was the following: from 0 to $6 \mathrm{~min}$, from 0 to $30 \% \mathrm{~A}$ in B (linear gradient); from 6 to $6.1 \mathrm{~min}$, from $30 \%$ to $0 \mathrm{~A}$ in $\mathrm{B}$ (linear gradient). A re-equilibration period of 2 min was used between individual runs. Elution was carried 
out at $40^{\circ} \mathrm{C}$, with a flow rate of $0.4 \mathrm{~mL} / \mathrm{min}$ and detection at $530 \mathrm{~nm}$.

Three anthocyanins were used as reference compounds: cyanidin 3-O-glucoside chloride $\left(\mathrm{C}_{21} \mathrm{H}_{21} \mathrm{ClO}_{11}\right)$, with a relative molecular mass of 484.84 and a purity of $95 \%$; delphinidin $\left(\mathrm{C}_{15} \mathrm{H}_{11} \mathrm{ClO}_{7}\right)$, with a relative molecular mass of 338.7 and a purity of $95 \%$; and pelargonidin 3-O-glucoside chloride $\left(\mathrm{C}_{21} \mathrm{H}_{21} \mathrm{ClO}_{10}\right)$, with a relative molecular mass of 468.84 and a purity of $97 \%$. All of the standards were obtained from Sigma-Aldrich.

The material $(0.1 \mathrm{~g})$ was pulverized and extracted at room temperature, with a mixture composed of methanol:hydrochloric acid (1000:8.6). The solutions were dissolved by the same volume of solvent B, and filtered through $0.45-\mu \mathrm{m}$ filters (J.T. Baker) before being injected into the chromatographic column.

\section{RESULTS}

\section{Phenotypic analyses of transgenic plants}

We observed the bud and petal color of the transgenic plants, together with the untransformed control. As shown in Figure 1, the cultivar 9702 produced red flowers with yellow anthers, whereas the overexpression of $C a D F R$ transformants displayed multiple phenotypes, including red flowers with pink stripes (9H31), red flowers with pink spots (9H30), and deepred flowers with purple anthers (9H33). The RoDFR transformants of 9702 had similar changes as the $C a D F R$ transformants, except that flowers with pink stripes did not occur.

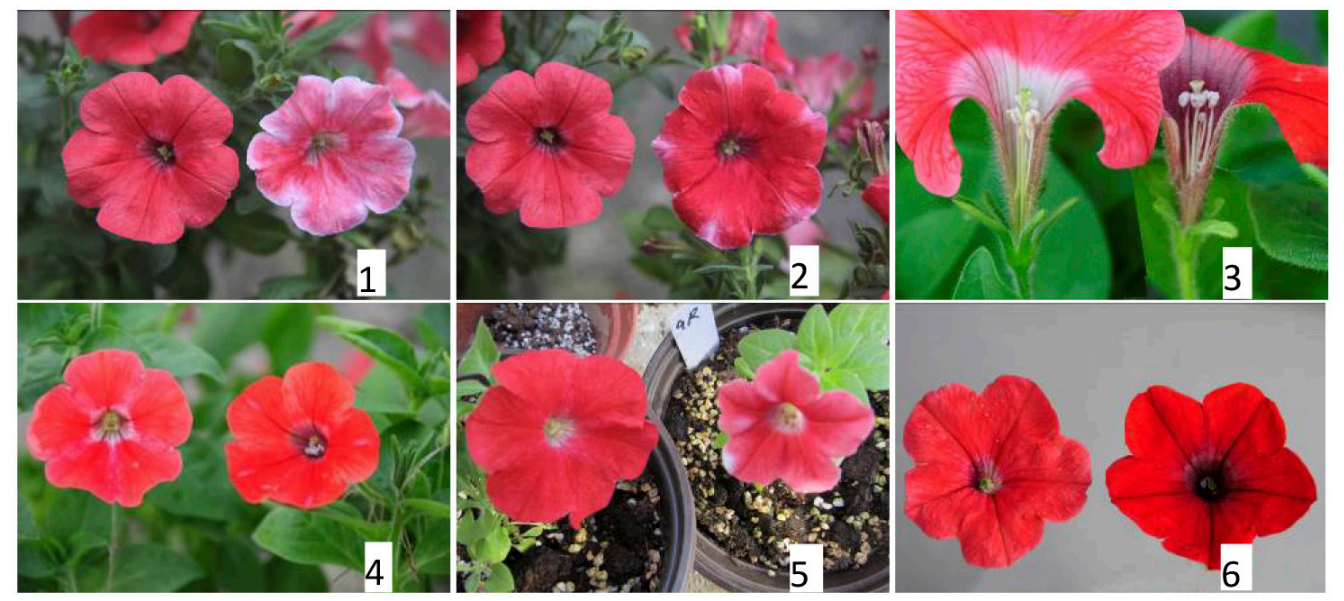

Figure 1. Phenotypes of different transformants. 1. Left is 9702, right is 9H31, a red flower with pink stripes; 2. left is 9702 , right is $9 \mathrm{H} 30$, a red flower with pink spots; 3 . left is 9702 , right is $9 \mathrm{H} 33$, purple anthers; 4 . left is 9702 , right is $9 \mathrm{H33}$, a deep-red flower; 5. left is 9702 , right is $9 \mathrm{R} 8$, a red flower with pink spots; 6. left is 9702 , right is 9R9, a deep-red flower.

\section{PeDFR expression characteristics in various tissues of 9702}

Expression analysis showed that PeDFR transcript expression was detected in all the tissues, but expression levels were significantly different (Figure 2). The highest level of 
PeDFR expression was observed in the anthers, which had almost twice the PeDFR expression level found in petals starting to open. The PeDFR expression level in petals starting to open was approximately 17.66-fold higher than that in the leaves, and in the buds it was much lower than in the petals starting to open. The PeDFR expression level in fully opened flowers was lower than in petals starting to open.

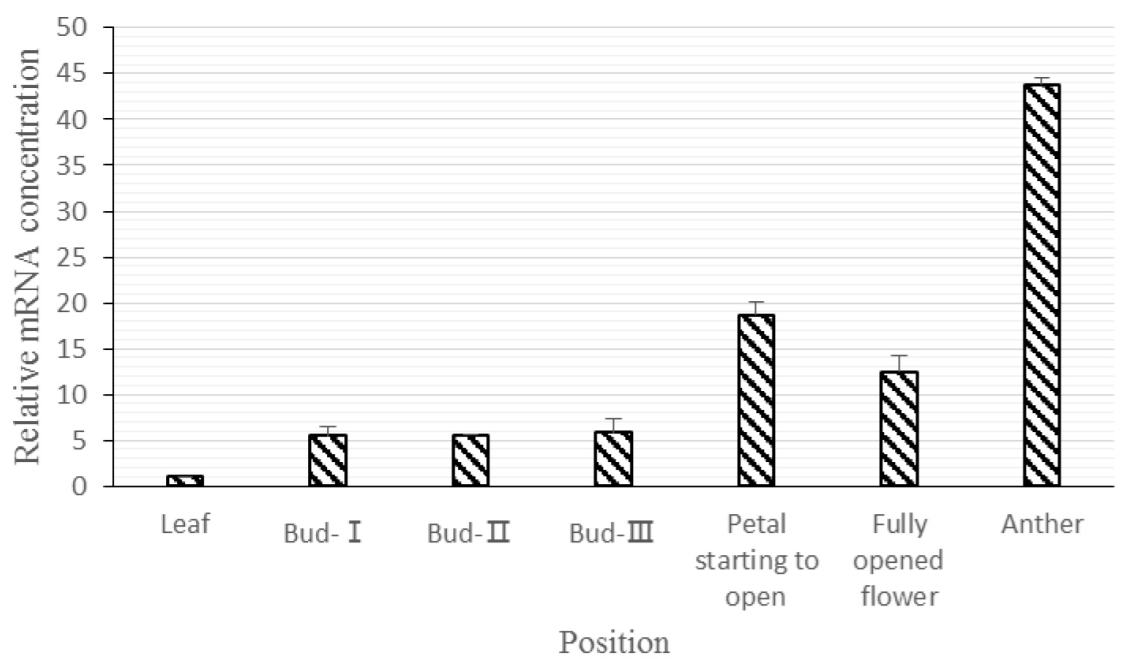

Figure 2. $P e D F R$ expression changes in various tissues of 9702. The expression level of PeDFR was low in the leaves, then increased in flower bud types I and II and in petals starting to open. The highest expression level was found in the anthers.

The highest DFR activity was observed in petals starting to open, whereas in fully opened flowers DFR activity was low. There was no DFR activity in the leaves or anthers, and only low activity in the flower buds (types I, II, and III) (Figure 3).

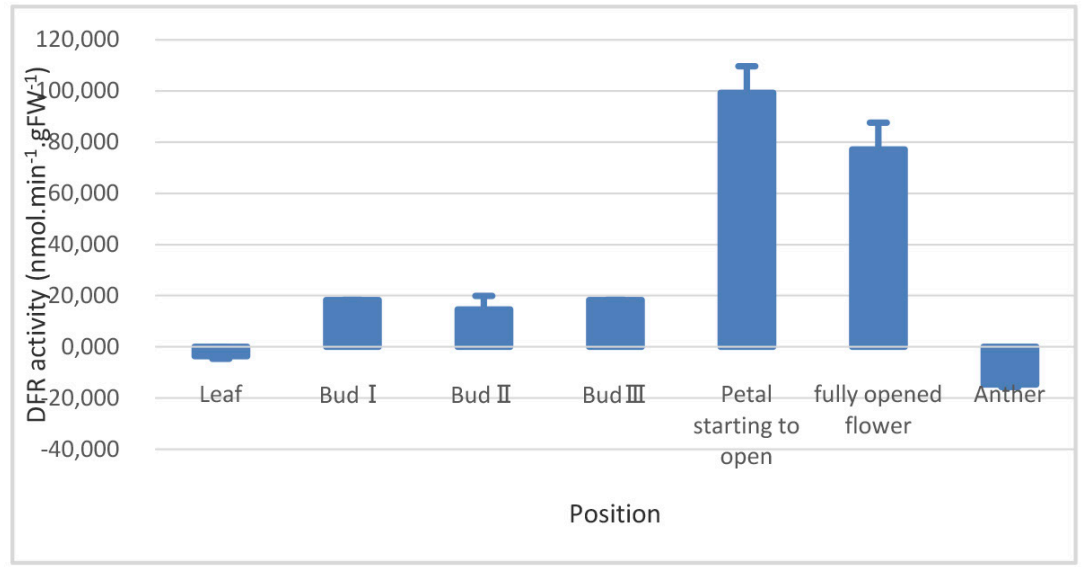

Figure 3. Dihydroflavonol 4-reductase (DFR) enzyme activity in different tissues of petunia 9702 . There was no DFR activity in the leaves or anthers, and only low DFR activity was found in the flower buds. The highest DFR activity was found in petals starting to open, before decreasing in fully opened flowers. 
In cultivar 9702, DFR enzyme activity and the DFR mRNA concentration followed a similar trend, except in the anthers, the mRNA concentration was high where DFR enzyme activity was also high, and vice versa. Calculations revealed that there was a positive, linear relationship between them:

DFR enzyme activity $=6.3638 \times$ relative mRNA concentration -14.776

The correlation coefficient $\left(\mathrm{R}^{2}\right)$ was 0.9685 (Figure 4).

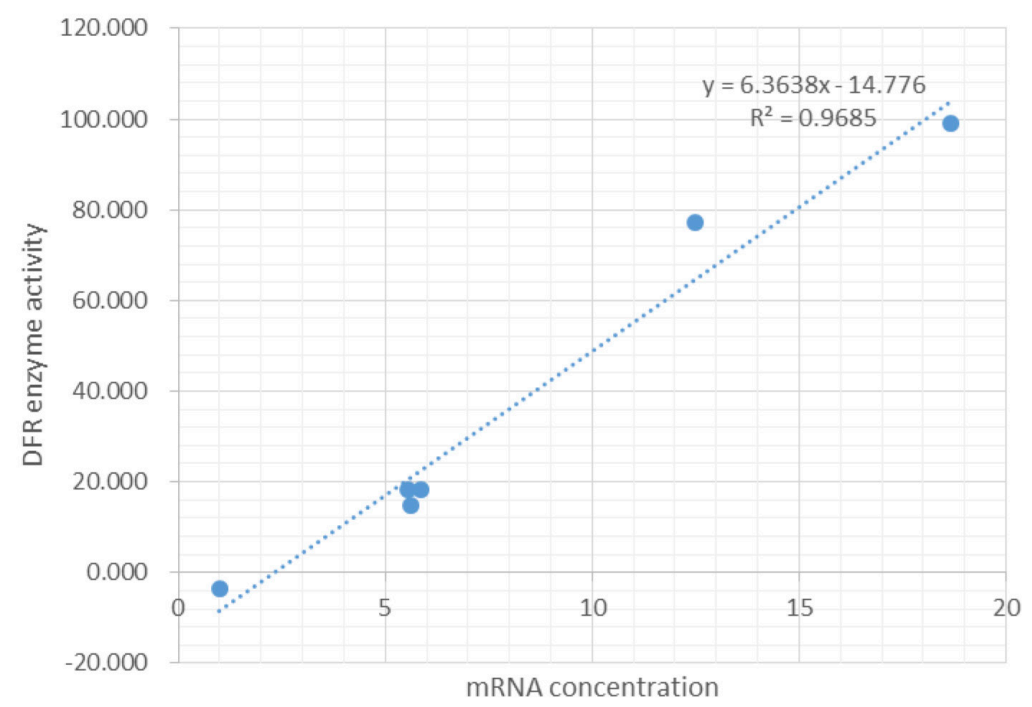

Figure 4. Linear regression. There was a positive, linear relationship between dihydroflavonol 4-reductase (DFR) enzyme activity and the relative concentration of mRNA in petunia 9702.

\section{CaDFR expression characteristics in various tissues of $9 \mathrm{H33}$}

CaDFR expression was detected in all of the tested tissues of $9 \mathrm{H} 33$, but expression levels were significantly different (Figure 5A). There was almost no expression in the leaves and anthers, and CaDFR was expressed at a low level in flower bud types I and III and at a high level in other tissues; expression levels differed by approximately 29-fold in petals starting to open between CaDFR in $9 \mathrm{H} 33$ and PeDFR in 9702.

The DFR enzyme activity was changed because it was integrated with $C a D F R$, and DFR enzyme activity had a similar variation to contrast (Figure 5A). That was, low enzyme activity was observed in the leaves, anthers, and flower bud type I. Enzyme activity increased in flower bud type II, but the highest activity was found in petals starting to open; it decreased in fully opened flowers. Enzyme activity was 2-fold higher in petals starting to open than in the controls.

\section{RoDFR expression characteristics in various tissues of 9R9}

RoDFR expression was detected in all of the tested tissues of 9R9, but expression levels were strikingly different (Figure 5B). There was almost no expression in the anthers, and 
only a low level of expression in flower bud types II and III. RoDFR expression in flower bud type I was high, but was lower in the leaves and fully opened flowers. The highest expression level was approximately 832-fold higher than that of the PeDFR expression level in 9702.

A

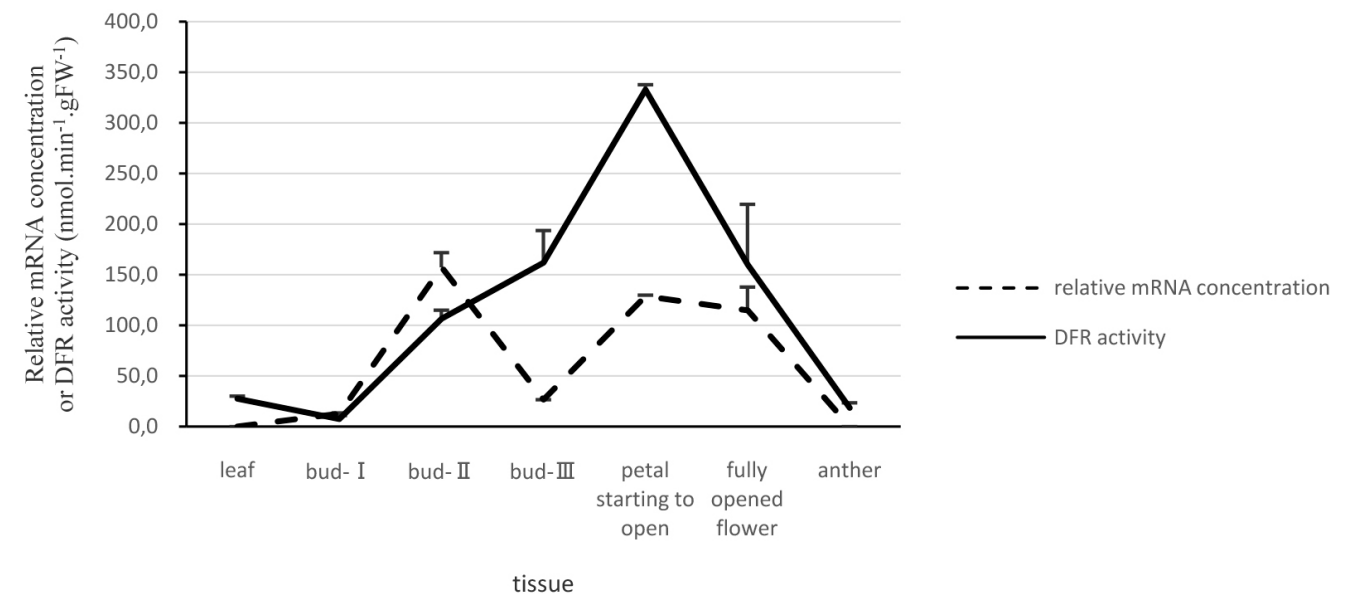

B

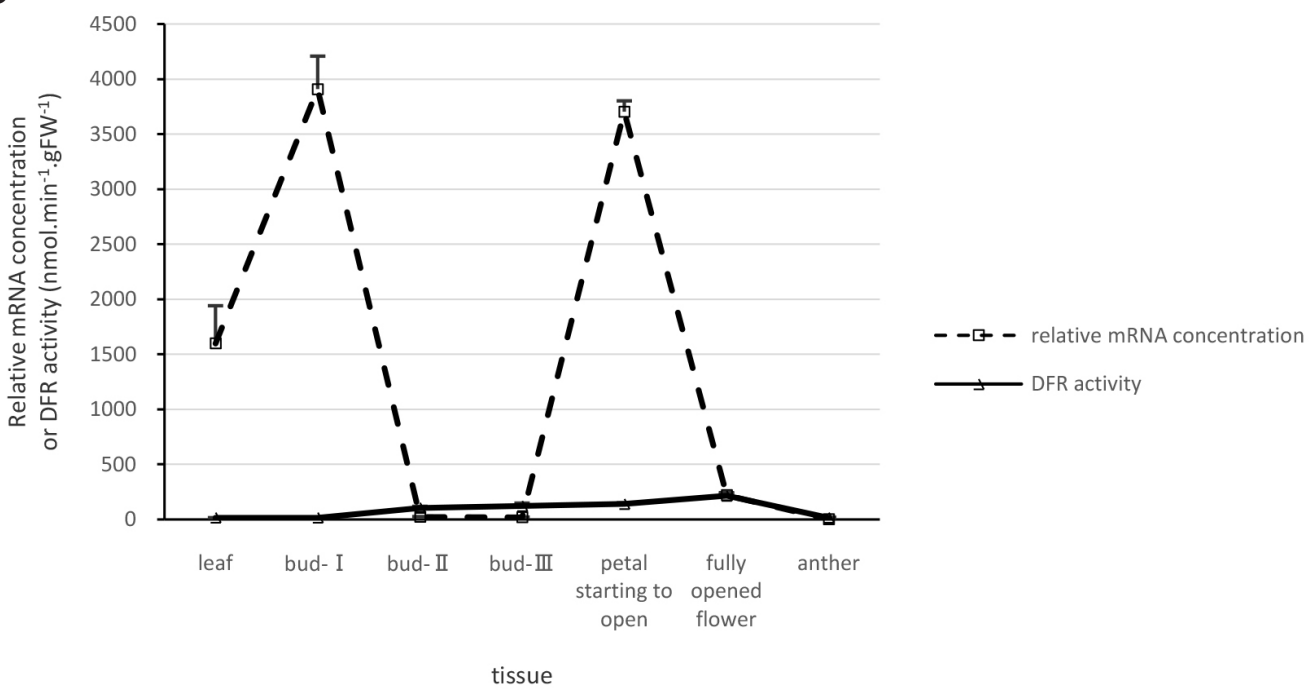

Figure 5. Relative dihydroflavonol 4-reductase (DFR) mRNA concentration and enzyme activity in different tissues. A. The transformant was $9 \mathrm{H} 33$; the changes in DFR enzyme activity were similar to those observed in the control; the relative DFR mRNA concentration was high from the flower bud type II stage onwards. B. The transformant was 9R9; the relative DFR mRNA concentration was significantly higher than that in the control, and had two peak values: in flower bud type I, and in petals starting to open. Enzyme activity increased from the flower bud type II stage, and the highest enzyme activity was found in fully opened petals.

The integration with RoDFR could change DFR enzyme activity significantly (Figure 5B). Low enzyme activity levels were observed in leaves, anthers, and flower bud type I, but 
they were higher than those in the control. Enzyme activity increased from flower bud type II, and the highest activity was found in fully opened petals $\left(214.9747 \mathrm{nmol} . \mathrm{g}^{-1} \mathrm{~min}^{-1}\right)$.

In different tissues of a transgenic plant with different DFRs under the control of a CaMV 35S promoter, exogenous DFR expression could be detected and expression levels were significantly altered. Although the highest expression levels of the two DFR genes was found in different tissues, both exhibited a relatively high expression level in petals starting to open. Enzyme activity in the $9 \mathrm{H} 33$ flower buds and petals starting to open was higher than in the same tissue of 9R9, and it significantly increased in petals starting to open, and then sharply decreased in fully opened petals, in which the activity was lower than that in 9R9.

\section{DFR enzyme activity and anthocyanin content in transformants}

The DFR enzyme activity in petal extracts of different primary petunia transformants is shown in Table 1. A wide range of activity was detected in six transgenic lines containing the $D F R$ gene. The highest activity was found in line $9 \mathrm{R} 12$, which was approximately 3 -fold higher than that found in 9702 . No activity was detected in the anthers of 9702.

\begin{tabular}{lcc} 
Table 1. Dihydroflavonol 4-reductase (DFR) enzyme activity in transformants and 9702. \\
\hline Sample & $\Delta \mathrm{A}$ & Activity $\left(\mathrm{nmol}^{\left.-\mathrm{min}^{-1} \cdot \mathrm{gFW}^{-1}\right)}\right.$ \\
\hline Petal of 9702 & $0.029 \pm 0.003$ & $106.569 \pm 10.394$ \\
Petal of 9H33 & $0.044 \pm 0.001$ & $159.853 \pm 5.197$ \\
Anther of 9H33 & $0.005 \pm 0.001$ & $18.374 \pm 5.197$ \\
Petal of 9H30 & $0.028 \pm 0.002$ & $104.731 \pm 7.795$ \\
Petal of 9H31 & $0.024 \pm 0.001$ & $86.357 \pm 2.598$ \\
Petal of 9R8 & $0.054 \pm 0.001$ & $194.438 \pm 5.197$ \\
Petal of 9R9 & $0.038 \pm 0.003$ & $139.642 \pm 10.394$ \\
Petal of 9R12 & $0.103 \pm 0.008$ & $378.502 \pm 31.182$ \\
\hline
\end{tabular}

Means \pm SD are reported.

The anthocyanin UPLC results show that anthocyanin compounds significantly increased in the petals and anthers of 9H33 (Table 2). The concentration of cyanidin 3-O-glucoside was twice higher than that in 9702, and a novel anthocyanin, pelargonidin 3-O-glucoside, was found in both petals and anthers [99.61 mg/kg fresh weight (petals), $44.23 \mathrm{mg} / \mathrm{kg}$ fresh weight (anthers)]. It appears that $C a D F R$ has a strong catalytic effect on DHM, and can also catalyze DHK, indicating that $D F R$ gene expression was responsible for anthocyanin change.

The cyanidin 3-O-glucoside concentration in the petals of 9R9 increased markedly, to approximately 1.15 times higher than that in $9702 ; 93.74 \mathrm{mg} / \mathrm{kg}$ fresh weight pelargonidin 3-O-glucoside was also detected. These results show that the catalytic substrate of RoDFR is similar to that of $C a D F R$.

The DFR enzyme activity of $9 \mathrm{H} 31$ and $9 \mathrm{H} 30$ was lower than that of 9702 , and the cyanidin 3-O-glucoside concentrations were also lower than in 9702. The anthocyanin content covaried with the DFR enzyme activity. DFR enzyme activity in 9R12 also considerably increased, to around 2.6 times that of 9702.

The expression of RoDFR in 9R8 was very low, but it had a dramatic effect on enzyme activity; it increased $82.4 \%$ more than that in 9702 . In line $9 R 8$, the concentrations of cyanidin 3-O-glucoside are increased and pelargonidin 3-O-glucoside was also produced. In 9R12 and 9R9, the concentration of cyaniding 3-glucoside also dramatically increased and more pelargonidin 3-O-glucoside was synthesized; it was 5-10-fold higher than that in 9R8. 
Table 2. Anthocyanin determination by ultra-performance liquid chromatography ( $\mathrm{mg} / \mathrm{kg}$ fresh weight).

\begin{tabular}{|c|c|c|c|c|}
\hline Sample & Cyanidin 3-O-glucoside & Delphinidin & Pelargonidin 3-O-glucoside & Total \\
\hline Petal of 9702 & $469.91 \pm 65.64$ & $60.62 \pm 8.68$ & nd & $530.53 \pm 73.24$ \\
\hline Anther of 9702 & $29.99 \pm 8.51$ & $22.44 \pm 3.75$ & nd & $52.43 \pm 13.04$ \\
\hline Petal of $9 \mathrm{H} 33$ & $1515.23 \pm 108.07$ & $65.34 \pm 10.42$ & $99.61 \pm 5.14$ & $1680.17 \pm 104.11$ \\
\hline Anther of $9 \mathrm{H} 33$ & $161.00 \pm 35.85$ & nd & $44.23 \pm 8.58$ & $205.44 \pm 44.28$ \\
\hline Petal of $9 \mathrm{H} 30$ & $397.62 \pm 11.58$ & $29.72 \pm 1.73$ & nd & $427.345 \pm 9.98$ \\
\hline Petal of $9 \mathrm{H} 31$ & $366.96 \pm 69.24$ & $48.40 \pm 7.10$ & nd & $415.36 \pm 68.52$ \\
\hline Petal of 9R8 & $478.081 \pm 8.922$ & $82.381 \pm 20.914$ & $9.198 \pm 0.776$ & $569.659 \pm 28.258$ \\
\hline Petal of 9R9 & $1012.93 \pm 69.07$ & $68.41 \pm 15.37$ & $93.74 \pm 4.22$ & $1175.08 \pm 57.46$ \\
\hline Petal of 9R12 & $1064.892 \pm 125.320$ & $23.036 \pm 5.797$ & $47.273 \pm 1.270$ & $1135.201 \pm 128.431$ \\
\hline
\end{tabular}

Means \pm SD are reported; $n d=$ not detected.

DFR enzyme activity in 9R12 was 0.95 -fold higher than that in 9R8, and the anthocyanin concentration followed a similar trend. In most of the transformants, changes in anthocyanin concentrations were similar to changes in DFR activity.

These results suggest that a change in the anthocyanin content of transgenic petunias was the main reason for the flower color change, and a strong correlation between anthocyanin content and DFR enzyme activity was found. Therefore, the change in flower color was probably the result of a DFR enzyme change.

\section{DISCUSSION AND CONCLUSION}

Both of the transformants that were integrated with DFR from C. hybrida and $R$. chinensis had deep-red flowers and purple anthers, and their anthocyanin content was similar. However, both $D F R$ transformants also had a line that had red flowers with pink spots. Pelargonidin 3-O-glucoside was found in 9H33, 9R8, 9R9, and 9R12, indicating that both CaDFR and RoDFR could catalyze DHK.

Introducing heterologous $D F R$ genes into petunias in order to change flower color was first described in the early 1990s, and DFRs from different plants were used (van der Krol et al., 1990; Tanaka et al., 1995; Tsuda et al., 2004). Although orange petunias have been developed by expressing maize, gerbera, and rose DFR genes in petunia accumulating DHK, it is not easy to obtain DHK-accumulating commercial varieties with recessive in F3'5' $\mathrm{H}$ (flavonoid 3',5'-hydroxylase), F3'H (flavonoid 3'-hydroxylase), or FLS (flavonol synthase). It is possible to down-regulate the $F 3^{\prime} 5^{\prime} H$ and $F^{\prime} H$ genes of transformants accumulating pelargonidin in order to obtain orange petunias. $D F R$ transgenic plants would show various degrees of change in flower color, due to the copy number or the integrated site. Stable transformants that accumulate pelargonidin are key to this method. The results indicate that the two DFRs were expressed in all of the petunia tissues, but their activity levels were different. These differences were probably caused by transcription regulation or activation. Because CaDFR and PeDFR are highly homologous, the adjustment mechanism in petunia may also affect $C a D F R$, so that the change in enzyme activity observed in $9 \mathrm{H} 33$ was similar to that in 9702 . The expression levels of RoDFR in several tissues of 9R9 were very high, while DFR enzyme activity in 9R9 was lower than that in $9 \mathrm{H} 33$. It is possible that because RoDFR is an unstable protein, it needs to synthesize more DFR to maintain the DFR protein concentration at a high level. Another possibility is that the activation efficiency of RoDFR in the petunia is low because of the difference between PeDFR and RoDFR; therefore, the DFR protein concentration should be 
increased in order to stimulate more activity. The exogenous $C a D F R$ transcription level was significantly lower than that of RoDFR. It is possible that any adverse effects on the petunia should be smaller than those when integrated with RoDFR.

The expression level of PeDFR in 9702 was highest in the anthers, possibly because of the high activity of the $d f r A$ gene (Huits et al., 1994); however, DFR activity was very low in the anthers, and consequently, they were yellow. A low exogenous DFR expression level would significantly increase enzyme activity, so that the anthers would be purple. Therefore, DFR plays a crucial role in the synthesis of anthocyanin in anthers. These results suggest that anther DFR is probably regulated by post-transcriptional regulation, such as having different splicing forms (similar to CHS in the petunia; Saito et al., 2006), or that its activation was inhibited. Another possible explanation for this anomaly could be that it indicates the presence of a very high level of $d f r B$ or $d f r C$, which are homologous genes of $d f r A$, which may be silent or may produce DFR-related transcripts with different catalytic properties, in different tissues, and at different times. The $d f r A$ gene is the only $D F R$ gene that exhibits any activity during flower development (Beld et al., 1989).

The DFR enzyme activity in the transformants was 5.6-7.8-fold higher than that in 9702, but the anthocyanin content was only 1.2-2.2-fold higher. This result indicates that the synthesis of anthocyanin is restricted by other anthocyanin biosynthesis enzymes. Although a large number of proanthocyanidins was synthesized, not all of them were modified to anthocyanin.

Nakatsuka et al. (2003) revealed that in anthocyanin-pigmented organs the DFR gene is always expressed, and $D F R$ expression patterns parallel increases in anthocyanin pigmentation in the tepals. Our results also show that the DFR enzyme has an important effect on the anthocyanin content; however, DFR expression occurs before anthocyanin synthesis.

\section{ACKNOWLEDGMENTS}

The authors would like to thank Qingxiong Rao (Shanghai Academy of Agricultural Sciences) for his help with anthocyanin UPLC detection. We also thank Shouguo Li and Yongchun Zhang for their excellent care of the plants.

\section{REFERENCES}

Beld M, Martin C, Huits H, Stuitje AR, et al. (1989). Flavonoid synthesis in Petunia hybrida: partial characterization of dihydroflavonol-4-reductase genes. Plant Mol. Biol. 13: 491-502.

Chen JC, Jiang CZ, Gookin TE, Hunter DA, et al. (2004). Chalcone synthase as a reporter in virus-induced gene silencing studies of flower senescence. Plant Mol. Biol. 55: 521-530.

Chu YX, Pan JS, Wu AZ, Cai R, et al. (2014). Molecular cloning and functional characterization of dihydroflavonol-4reductase gene from Calibrachoa hybrida. Sci. Hortic. 165: 398-403.

Elomaa P, Helariutta Y, Griesbach RJ, Kotilainen M, et al. (1995). Transgene inactivation in Petunia hybrida is influenced by the properties of the foreign gene. Mol. Gen. Genet. 248: 649-656.

Forkmann G and Ruhnau B (1987). Distinct substrate specificity of dihydroflavonol-4-reductase from flowers of Petunia hybrida. Zeitschrift fur Naturforschung C Bioscience 42: 1146-1148.

Hayashi M, Takahashi H, Tamura K, Huang J, et al. (2005). Enhanced dihydroflavonol-4-reductase activity and NAD homeostasis leading to cell death tolerance in transgenic rice. Proc. Natl. Acad. Sci. U. S. A. 102: 7020-7025.

Huits HSM, Gerats AGM, Kreike MM, Mol JNM, et al. (1994). Genetic control of dihydroflavonol 4-reductase gene expression in Petunia hybrida. Plant J. 6: 295-310.

Johnson ET, Yi H, Shin B, Oh BJ, et al. (1999). Cymbidium hybrida dihydroflavonol 4-reductase does not efficiently reduce dihydrokaempferol to produce orange pelargonidin-type anthocyanins. Plant J. 19: 81-85.

Johnson ET, Ryu S, Yi H, Shin B, et al. (2001). Alteration of a single amino acid changes the substrate specificity of 
dihydroflavonol 4-reductase. Plant J. 25: 325-333.

Katsumoto Y, Fukuchi-Mizutani M, Fukui Y, Brugliera F, et al. (2007). Engineering of the rose flavonoid biosynthetic pathway successfully generated blue-hued flowers accumulating delphinidin. Plant Cell Physiol. 48: 1589-1600.

Li HH, Qiu J, Chen FD, Lv XF, et al. (2012). Molecular characterization and expression analysis of dihydroflavonol 4-reductase (DFR) gene in Saussurea medusa. Mol. Biol. Rep. 39: 2991-2999.

Luczkiewicz M and Cisowski W (1998). The RP-HPLC analysis of anthocyanins. Chromatographia 48: 360-364.

Matsubara K, Kodama H, Kokubun H, Watanabe H, et al. (2005). Two novel transposable elements in a cytochrome P450 gene govern anthocyanin biosynthesis of commercial petunias. Gene 358: 121-126.

Meyer P, Heidmann I, Forkmann G and Saedler H (1987). A new petunia flower colour generated by transformation of a mutant with maize gene. Nature 330: 677-678.

Mol JNM, Holton TA and Koes RE (1995). Floriculture: genetic engineering of commercial traits. Trends Biotechnol. 13: 350-355.

Nakatsuka A, Izumi Y and Yamagishi M (2003). Spatial and temporal expression of chalcone synthase and dihydroflavonol 4-reductase genes in the Asiatic hybrid lily. Plant Sci. 165: 759-767.

Oud JSN, Schneiders H, Kool AJ and van Grinsven MQJM (1995). Breeding of transgenic orange Petunia hybrida varieties. Euphytica 85: 403-409.

Qi YY, Lou Q, Quan YH, Liu YL, et al. (2013). Flower-specific expression of the Phalaenopsis flavonoid 3',5'-hydroxylase modifies flower color pigmentation in Petunia and Lilium. Plant Cell Tiss. Org. Cult. 115: 263-273.

Saito R, Fukuta N, Ohmiya A, Itoh Y, et al. (2006). Regulation of anthocyanin biosynthesis involved in the formation of marginal picotee petals in Petunia. Plant Sci. 170: 828-834.

Schmittgen TD and Livak KJ (2008). Analyzing real-time PCR data by the comparative $\mathrm{C}_{\mathrm{T}}$ method. Nat. Protocols 3: 1101-1108.

Seo J, Kim SW, Kim J, Cha HW, et al. (2007). Co-expression of flavonoid 3' 5'-hydroxylase and flavonoid 3'-hydroxylase accelerates decolorization in transgenic chrysanthemum petals. J. Plant Biol. 50: 626-631.

Tanaka Y, Fukui Y, Fukuchi-Mizutani M, Holton TA, et al. (1995). Molecular cloning and characterization of Rosa hybrida dihydroflavonol 4-reductase gene. Plant Cell Physiol. 36: 1023-1031.

Tanaka Y, Katsumoto Y, Brugliera F and Mason J (2005). Genetic engineering in floriculture. Plant Cell Tiss. Org. Cult. 80: 1-24.

Tsuda S, Fukui Y, Nakamura N, Katsumoto Y, et al. (2004). Flower color modification of Petunia hybrida commercial varieties by metabolic engineering. Plant Biotechnol. 21: 377-386.

van der Krol AR, Mur LA, Beld M, Mol JN, et al. (1990). Flavonoid genes in petunia: addition of a limited number of gene copies may lead to a suppression of gene expression. Plant Cell 2: 291-299.

Yang FX, Cai J, Yang Y and Liu ZB (2013). Overexpression of microRNA828 reduces anthocyanin accumulation in Arabidopsis. Plant Cell Tiss. Org. Cult. 115: 159-167.

Yong WTL, Abdullah JO and Mahmood M (2009). Agrobacterium-mediated transformation of Melastoma malabathricum and Tibouchina semidecandra with sense and antisense dihydroflavonol-4-reductase (DFR) genes. Plant Cell Tiss. Org. Cult. 96: 59-67.

Zhou LL, Zeng HN, Shi MZ and Xie DY (2008). Development of tobacco callus cultures over expressing Arabidopsis PAP1/MYB75 transcription factor and characterization of anthocyanin biosynthesis. Planta 229: 37-51. 